\title{
Familial neurohypophyseal diabetes insipidus in 13 kindreds and 2 novel mutations in the vasopressin gene
}

\author{
Giuseppa Patti ${ }^{1, *}$, Saverio Scianguetta ${ }^{2, *}$, Domenico Roberti ${ }^{2}$, Alberto Di Mascio ${ }^{3}$, Antonio Balsamo ${ }^{4}$, \\ Milena Brugnara5 ${ }^{5}$, Marco Cappa ${ }^{6}$, Maddalena Casale ${ }^{2}$, Paolo Cavarzere5 ${ }^{5}$ Sarah Cipriani ${ }^{7}$, Sabrina Corbetta ${ }^{8}$, \\ Rossella Gaudino ${ }^{5}$, Lorenzo lughetti ${ }^{9}$, Lucia Martini ${ }^{5}$, Flavia Napoli' ${ }^{1}$, Alessandro Peri ${ }^{7}$, Maria Carolina Salerno ${ }^{10}$,

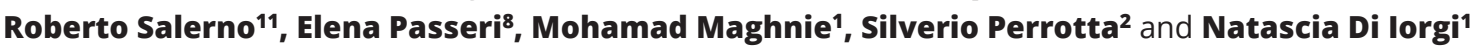

${ }^{1}$ Department of Pediatrics, IRCCS Istituto Giannina Gaslini Institute, University of Genova, Genova, Italy, ${ }^{2}$ Department of Women, Child and General and Specialized Surgery, University of Campania 'Luigi Vanvitelli', Naples, Italy, ${ }^{3}$ University of Trieste, Trieste, Italy,

${ }^{4}$ Pediatrics Unit, Policlinico S. Orsola-Malpighi, Bologna, Italy, ${ }^{5}$ Department of Surgical Sciences, Dentistry, Gynecology and Pediatrics, University of Verona, Verona, Italy, ${ }^{6}$ Unit of Endocrinology, Bambino Gesù Children's Hospital, IRCCS, Roma, Italy, ${ }^{7}$ Endocrine Unit, Department of Experimental and Clinical Biomedical Sciences 'Mario Serio', University of Firenze, Ospedale Careggi Firenze, Firenze, Italy, ${ }^{8}$ Endocrinology and Diabetology Service, IRCCS Istituto Ortopedico Galeazzi, University of Milan, Milan, Italy, ${ }^{9}$ Policlinico Universitario Modena, Modena, Italy, ${ }^{10}$ Department of Translational Medical Sciences-Pediatric Section, University of Naples Federico II, Naples, Italy, and ${ }^{11}$ SOD Endocrinologia, DAI Medico-Geriatrico, AOU Careggi Florence, Florence, Italy

*(G Patti and S Scianguetta contributed equally to this work)

Correspondence should be addressed to M Maghnie or S Perrotta Email mohamadmaghnie@gaslini. org or silverio.perrotta@ unicampania.it

\begin{abstract}
Background: Autosomal dominant neurohypophyseal diabetes insipidus (adNDI) is caused by arginine vasopressin (AVP) deficiency resulting from mutations in the AVP-NPII gene encoding the AVP preprohormone. Aim: To describe the clinical and molecular features of Italian unrelated families with central diabetes insipidus. Patients and methods: We analyzed AVP-NPII gene in 13 families in whom diabetes insipidus appeared to be segregating.

Results: Twenty-two patients were found to carry a pathogenic AVP-NPIl gene mutation. Two novel c.173 G>C (p.Cys58Ser) and c.215 C>A (p.Ala72Glu) missense mutations and additional eight different mutations previously described were identified; nine were missense and one non-sense mutation. Most mutations (eight out of ten) occurred in the region encoding for the NPII moiety; two mutations were detected in exon 1. No mutations were found in exon 3. Median age of onset was 32.5 months with a variability within the same mutation (3 to 360 months). No clear genotype-phenotype correlation has been observed, except for the c.55 G>A (p.Ala19Thr) mutation, which led to a later onset of disease (median age 120 months). Brain magnetic resonance imaging (MRI) revealed the absence of posterior pituitary hyperintensity in 8 out of 15 subjects, hypointense signal in 4 and normal signal in 2 . Follow-up MRI showed the disappearance of the posterior pituitary hyperintensity after 6 years in one case.

Conclusion: adNDI is a progressive disease with a variable age of onset. Molecular diagnosis and counseling should be provided to avoid unnecessary investigations and to ensure an early and adequate treatment.
\end{abstract}




\section{Introduction}

Central diabetes insipidus (CDI) is a heterogeneous condition characterized by polyuria and polydipsia due to a deficiency of arginine vasopressin (AVP). In many patients, especially children and adolescents, it is caused by the destruction or degeneration of the neurons that originate in the supraoptic and paraventricular nuclei of the hypothalamus. Germinoma (1, 2, 3, 4) craniopharyngioma (1, 2, 3, 4), Langerhans'-cell histiocytosis $(1,2,3,4,5)$, inflammatory, autoimmune $(1$, $2,3,4,5,6)$ /vascular diseases (6), brain malformations (7), trauma resulting from surgery or an accident $(1,2,3,4,5)$ and in rare cases autosomal dominant neurohypophyseal DI (adNDI) $(8,9,10,11,12)$ or X-linked recessive traits $(13$, $14,15)$ can cause permanent damage to supraoptic and paraventricular nuclei. The differential diagnosis of the above reported conditions, all presenting with hypotonic polyuria and polydipsia, is challenging and requires a long-term follow-up, including endocrine and imaging evaluations $(2,3)$ suggesting that early diagnosis of genetic conditions could avoid unnecessary investigations.

The frequency of adNDI due to AVP-neurophysin II (AVP-NPII) gene mutation is currently unknown, although autosomal dominant forms account for between 3.5 and $8 \%$ among reported series of patients with CDI $(1,3,9)$, but these data are skewed by differing inclusion criteria and the availability of genetic testing. Among 79 children with CDI of different etiologies, five of 41 patients (6\%) with isolated AVP deficiency and without other evolving pituitary dysfunctions over time, with a normal pituitary stalk size and normal central nervous system appearances were diagnosed with autosomal dominant CDI in one study (1), while three patients with autosomal dominant CDI (3.5\%) were identified among 85 CDI patients in a more recent one (3).

More than 70 disease-causing mutations resulting in a defective pro-hormone and a deficiency of AVP have been described in adNDI $(8,9,10,11,12,13,14,15$, $16,17,18,19,20,21,22,23,24,25,26,27,28,29,30)$. The AVP-NPII gene consists of three exons where exon 1 encodes the signal peptide, the AVP peptide and the first nine amino acids of NPII; exon 2 encodes the majority of NPII and exon 3 encodes the carboxyl-terminal 17 amino acids of NPII and copeptin. The pathophysiology could be explained by a progressive postnatal degeneration of the magnocellular neurons producing $\operatorname{AVP}(8,10,11,12,16)$. The severity of polyuria may vary considerably between different families and even among siblings carrying the same mutation. In fact, in adNDI, clinical disease onset typically ranges from the first to the sixth year of life, but various cases of early or delayed onset have also been reported (31). Symptoms usually worsen with time in patients with early onset of mild polyuria and polydipsia, especially before 10 years of age, but it is also possible that complete CDI is expressed from the neonatal period in patients with brain malformations (32).

The wide variability in the age of onset and the severity of the AVP deficiency among patients with the same mutation may be ascribed to individual differences among such patients, like the rate of production of the mutant precursor, the intensity of neurohypophyseal stimulation, individual susceptibility to the toxic effect of the mutant precursor, the ability to degrade mutant precursors and variations in secretory reserve capacity or in the development of the gland itself $(8,9,10,11,12,13$, $14,15,16,17,18,19,20,21,22,23,24,25,26,27,28,29$, 30). Recent data demonstrated that although autophagy should primarily be a protective mechanism, continuous autophagy leads to gradual loss of organelles including endoplasmic reticulum (ER), resulting in autophagyassociated cell death of AVP neurons in mice with familial NDI (33).

Aim of this study was to investigate the presence of mutations in the AVP-NPII gene in 13 families with clinical diagnosis of CDI. Establishing the genetic etiology of CDI enables early appropriate management and family counseling and could be useful to avoid unnecessary neuroimaging follow-up.

\section{Patients and methods}

We studied 22 members of 13 Italian families, in whom CDI appeared to be segregating. The family history was described by a pedigree covering the indicated number of generations (Fig. 1). Patients were referred by eight Italian Pediatric Endocrine Units (Istituto Giannina Gaslini Genova, Federico II University Napoli, Ospedale Bambino Gesù Roma, Policlinico San Donato Milan, Policlinico Verona, Policlinico S. Orsola-Malpighi Bologna, Policlinico Modena, Ospedale Careggi Firenze) between January 2003 and April 2016.

The diagnosis of CDI was based on a standard protocol as reported previously (3); the criteria for the enrolment of patients were (1) isolated AVP deficiency and (2) family history of CDI. Brain MRI studies in T1-weighted sequences were performed in 15 subjects. MRI was performed at the time of diagnosis and was repeated during follow-up in one patient. 
Family 1A

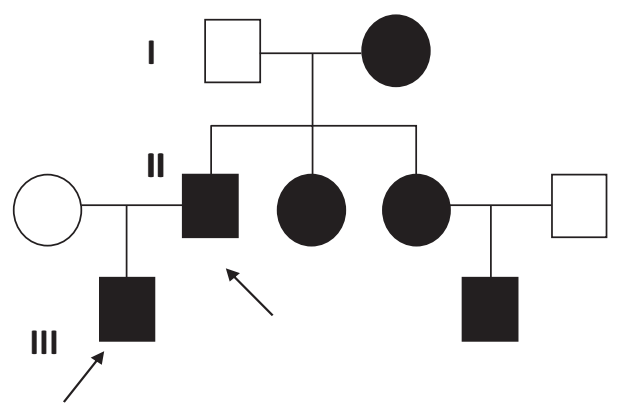

Family 4D

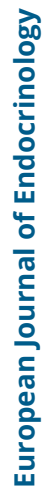

Family 2 B

Family 3 C

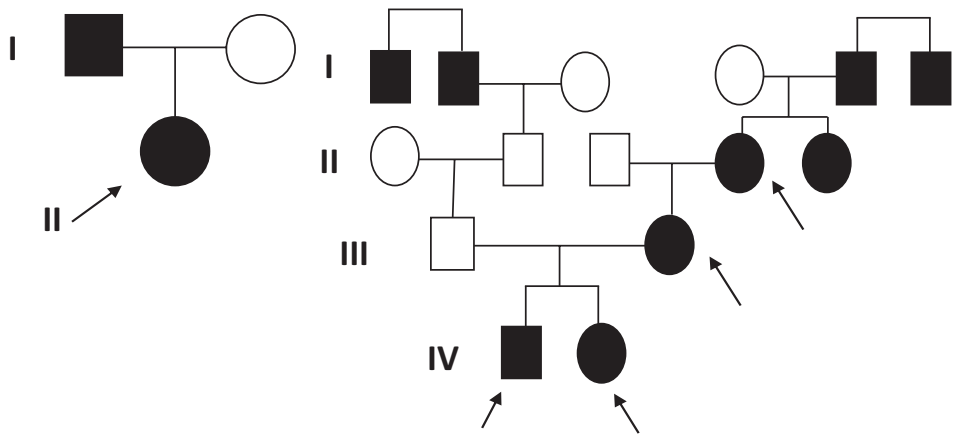

Family $5 E$

Family 6 F


III

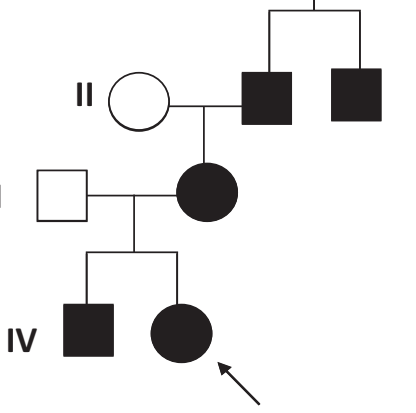

Family $8 \mathrm{H}$

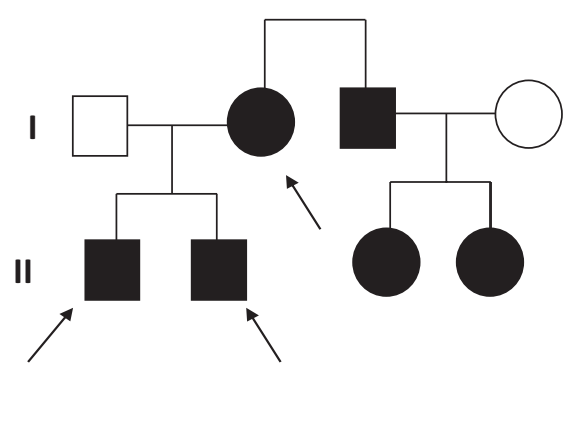

Family $12 \mathrm{~L}$

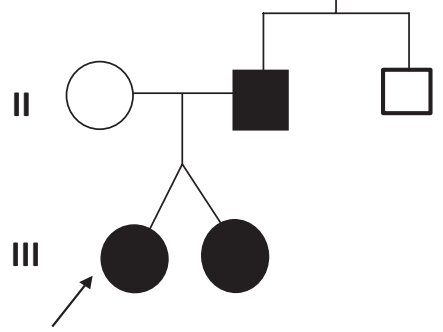

Family $11 \mathrm{~K}$

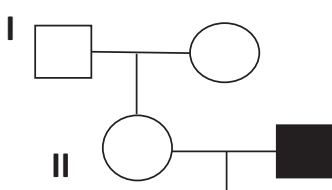

Family $13 \mathrm{M}$

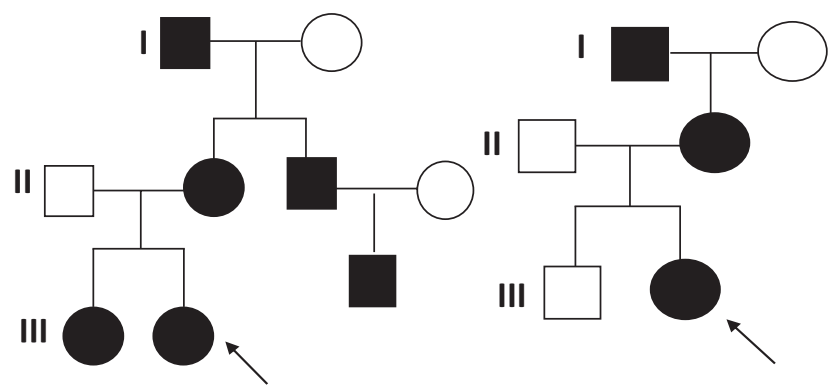

II
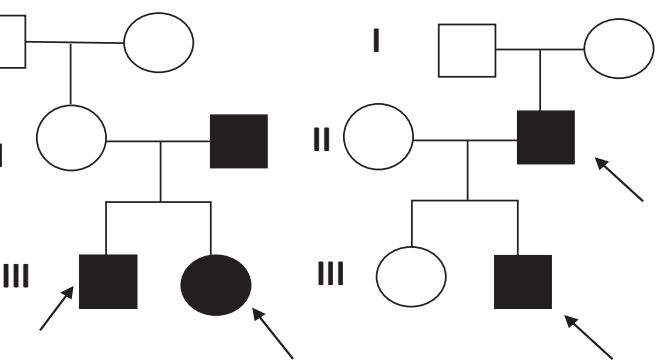

Figure 1

Pedigrees of the 13 families (A-M). Affected individuals who underwent genetic testing are indicated by the arrows; circles denote females, squares denote males. 
The pituitary-thyroid-adrenal axis was assessed by measuring serum free thyroxine, thyrotropin and serum cortisol once every 6-12 months. Growth hormone deficiency was ruled out based on the presence of normal growth. This study was approved by the Institutional Review Board of 'Istituto Giannina Gaslini', Genova, and written informed consent was obtained from the patients and/or their parents.

Two-hundred healthy individuals as well as the unaffected family members of the respective kindreds were screened for all the AVP-NPII gene mutations.

\section{Nucleotide sequences of exons of AVP-NPII gene}

Genetic analyses were performed at the Pediatric Unit of the 'Department of Woman, Child and General and Specialized Surgery' of the University of Campania 'L. Vanvitelli'.

\section{Detection of gene mutation: PCR amplification of AVP-NPII exons}

Genomic DNA was isolated from peripheral blood leukocytes using Extraction DNA Kit (Qiagen) in accordance with the manufacturer's instruction. To identify genetic variants, all three exons of the AVP-NPII (OMIM ID: 192340; ENSEMBL ID: ENSG00000101200) were amplified in $25 \mu \mathrm{L}$ reactions containing $100 \mathrm{ng}$ of genomic DNA. Intronic PCR primer pairs lying about $100 \mathrm{bp}$ external to each intron/exon boundary were designed to amplify each exon using Primer3 design package. Exons were PCR amplified using standard conditions. Briefly, reactions comprised $10 \times$ buffer, dNTP stock containing $2.5 \mathrm{mM}$ dNTP, $25 \mathrm{mM}$ magnesium chloride, $5 \mu \mathrm{M}$ forward primer stock and reverse primer, $1 \mathrm{U}$ Taq Super Yield, 100ng genomic DNA template and sterile distilled water to $25 \mu \mathrm{L}$ (final volume). The thermal cycling was $95^{\circ} \mathrm{C}$ for $5 \mathrm{~min}$ followed by 35 cycles of $95^{\circ} \mathrm{C}, 30 \mathrm{sec}, 60^{\circ} \mathrm{C}, 45 \mathrm{sec}, 72^{\circ} \mathrm{C}$ $45 \mathrm{sec}$ and a final extension at $72^{\circ} \mathrm{C}$ for $5 \mathrm{~min}(7)$.

\section{Direct DNA sequencing of PCR products}

The reaction products were then purified using a QIAquick Gel Extraction Kit (Qiagen $\mathrm{GmbH}$ ) and sequencing was performed using the Big Dye Terminator (Applied Biosystems) on automated DNA capillary sequencer (ABI PRISM 310, Applied Biosystems).

Primers:

- AVP_Ex1F TGCAGTCACAGTAGAGGCAA

- AVP_Ex1R TACCACCACCCATGACTTCC
- AVP_Ex2F GGGTTCTGGATGGGTAGGG

- AVP_Ex2R GGTAGTTCTCCTCCTGGCAG

- AVP_Ex3F CTTCGGGCCCAGCATCTG

- AVP_Ex3R TTtATtGTCCGTGCTGCAGG

\section{Summary of genetic and clinical findings}

We analyzed 22 members of 13 Italian families with CDI and median age of onset of 32.5 months (3-360 months), who were found to carry a pathogenic AVP-NPII gene mutation. Two novel mutations were detected in two families, and eight other different mutations, all known to be associated with adNDI, were documented in the other ones (Fig. 2). The new mutations were not found in 200 healthy controls and in the unaffected family members of the respective patients. Sequencing chromatograms containing the identified variants are shown in Fig. 3. Nine were missense mutations and 1 a nonsense mutation with 8 of 10 occurring in the gene regions encoding the NPII moiety; 2 mutations were detected in exon 1 and no mutations were found in exon 3. Subjects carrying c.55G $>$ A - (p.Ala19Thr) and c.173 G>C (p.Cys58Ser) mutations were found to have a later onset of disease at a median age of 120 months (120-132 months). Clinical and biochemical evaluations demonstrated that polyuria and polydipsia were the only symptoms at disease onset, and none of the patients showed either severe hypernatremia or growth delay. Neither hyponatremia $(\mathrm{Na}<135 \mathrm{mEq} / \mathrm{L})$ nor seizures were reported under desmopressin treatment.

\section{Family $1 \mathrm{~A}$}

The index case is a 13-year-old-boy with polyuria and polydipsia from the age of 32 months. Six members from three generations (the father, paternal grandmother, two paternal aunts and a paternal cousin) reported symptoms and signs of DI, and the pattern of inheritance was consistent with an autosomal dominant mode (Fig. 1). The patient enjoyed relatively good health and his growth was normal. MRI showed an absent posterior pituitary hyperintensity (PPI). Genetic analysis performed in the index case and in his father revealed a previously described c.164 C>T (p.Pro55leu) mutation (Fig. 3 and Table 1).

\section{Family 2 B}

The index case is a 16-year-old girl with a history of polyuria and polydipsia from the age of 30 months. Water deprivation test and desmopressin (dDAVP) test were performed confirming the diagnosis of CDI. Her father was 


\begin{tabular}{|l|l|l|l|l|}
\hline SP & AVP & Exon 1 & Exon 3 \\
\hline
\end{tabular}
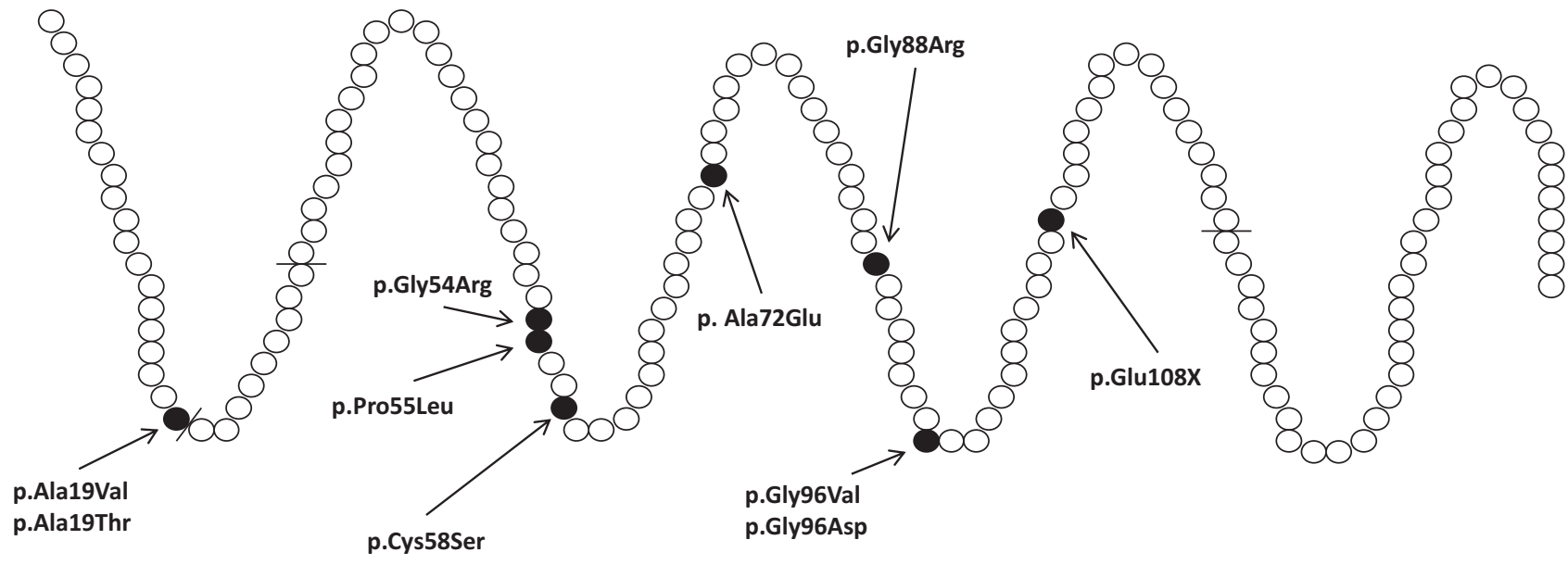

\section{Figure 2}

Schematic diagram of the coding regions of the vasopressin-neurophysin II gene. The location and type of mutations associated with familial central diabetes insipidus identified are represented and indicated by the arrows.

also affected by CDI and showed polyuria and polydipsia from the age of 6 years (72 months) (Fig. 1). Brain MRI was performed that showed a normal anterior pituitary and pituitary stalk with absent PPI (Table 2). Genetic analysis revealed a c.322G>T (p.Glu108X) nonsense mutation (Fig. 3 and Table 1).

\section{Family 3 C}

Two siblings, a 3-year-old male and a 4-year 9 monthold-female showed polyuria and polydipsia from the age of 9 months and 16 months, respectively. They had a family history of CDI. Their mother had onset of polyuria and polydipsia from the age of 24 months, whereas their grandmother had clinical manifestations of DI in adulthood (30 years) (Fig. 1). The parents were not consanguineous. Water deprivation test and dDAVP test confirmed the diagnosis of CDI. Brain MRI performed in the boy and in his mother showed a lack of PPI in both patients and anterior pituitary hypoplasia in the boy. The direct sequencing of the AVP-NPII gene showed a point mutation (c.287G>A, p.Gly96Asp) in a heterozygous state, confirming the diagnosis of adNDI (Fig. 3 and Table 1). In addition, the boy showed hypokalemia, metabolic alkalosis, hyperreninemia and hyperaldosteronism. Plasma magnesium concentration was slightly low.
Urine analysis showed hypercalciuria, hyposthenuria and high excretion of potassium. Since adNDI did not explain the boy's phenotype, genetic analysis for Gitelman syndrome was performed that confirmed the combination of Gitelman syndrome and adNDI.

\section{Family 4 D}

The index case is a 17-year-boy with polyuria from the age of 33 months and a family history of CDI in his paternal lineage (Fig. 1). He had a sister with polyuria and polydipsia from the age of 22 months. The two siblings underwent water deprivation and the dDAVP tests that confirmed the diagnosis of CDI. Genetic analysis performed in the index case showed a c164C>T (p.Pro55Leu) missense mutation (Fig. 3 and Table 1). Brain MRI was normal in the boy, whereas the PP signal was hypointense in the girl (Table 2).

\section{Family 5 E}

The index patient is a 7-year-old girl with a history of polyuria, nycturia and polydipsia since she was aged 2 years. Blood examinations showed hypernatremia and urinary hypo-osmolality with OsmU/OsmP ratio $<1$, both corrected after dDAVP administration confirming the diagnosis of CDI. 
Families A / D

c.164C>T (p.Pro55Leu)

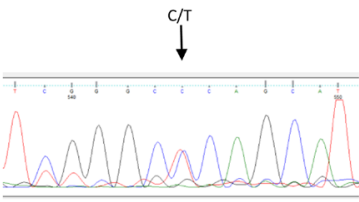

Family E

c.56C>T (p.Ala19Val)

$\stackrel{\mathrm{C} / \mathrm{T}}{\downarrow}$

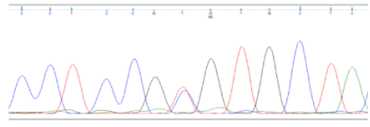

Family H

c.160G>C (p.Gly54Arg)

$\mathrm{G} / \mathrm{C}$

$\downarrow$

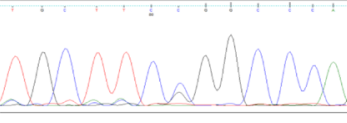

Family B

c.322G>T (p.Glu108X)
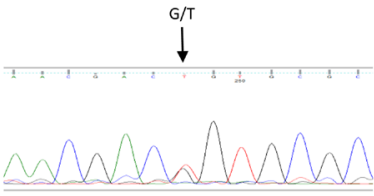

Family F

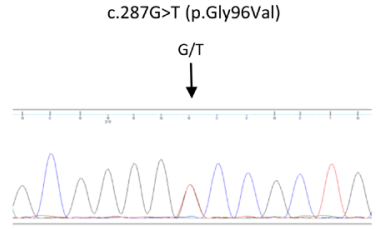

Families I /J/ K

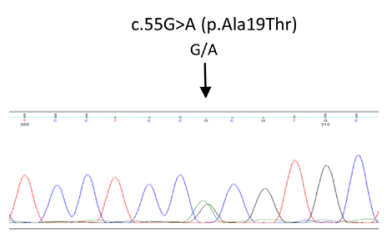

Family C

c.287G>A (p.Gly96Asp)

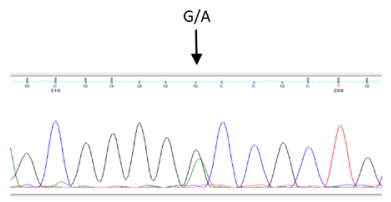

Family G

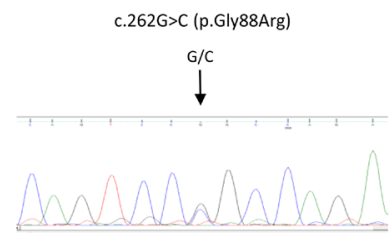

Family L

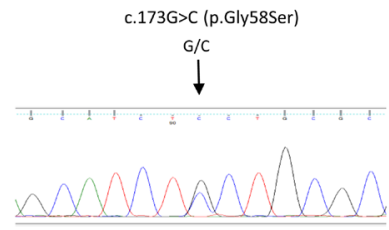

Family M

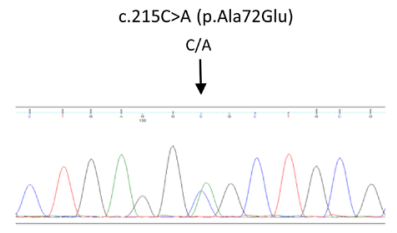

\section{Figure 3}

Sequencing chromatograms obtained by automated dye-terminator sequencing of the vasopressin-neurophysin II gene in the patients. A full colour version of this figure is available at https://doi.org/10.1530/EJE-19-0299.

Her growth had always been in the normal range, with a height at the $50^{\circ}$ centile according to her target height. Her father had a history of polyuria and polydipsia since his first years of life (Fig. 1). Genetic analysis showed a previously described c.56C $>\mathrm{T}$ (p.Ala19Val) mutation (Fig. 3 and Table 1). Interestingly, while the first brain MRI that was performed in the girl at the time of diagnosis showed the presence of normal PPI, a second MRI performed 6 years later showed a disappearance of the PP signal (Table 2 and Supplementary material, see section on supplementary data given at the end of this article).

\section{Family 6 F}

A 19-year-old female showed polyuria and polydipsia from the age of 3 years. A water deprivation test demonstrated a defect in urine concentrating ability, with a peak plasma osmolality of $300 \mathrm{mosmol} / \mathrm{kg}$ and urine osmolality below $300 \mathrm{mosmol} / \mathrm{kg}$; dDAVP led to resolution of symptoms, confirming the diagnosis of CDI. Her mother and her 13-year-old brother also had symptoms of DI (Fig. 1). The water deprivation test was stopped in the brother because of a significant weight loss $>5 \%$. Brain MRI revealed the absence of PPI in the three patients (Table 2). Genetic analysis performed in the index case showed a previously described c.287G>T (p.Gly96Val) missense mutation (Fig. 3 and Table 1).

\section{Family 7 G}

The index case is an 11-year-old girl with polyuria and polydipsia from the first years of life. Laboratory test showed hypernatremia, high serum osmolality and low urinary osmolality, which did not increase after water deprivation test. She showed a good response to desmopressin treatment, which confirmed the diagnosis of CDI. The neuroimaging study revealed a normal anterior pituitary and a decreased PP signal intensity. Because of her family history of familial DI (father, paternal grandfather and her paternal uncle) (Fig. 1), genetic analysis was performed showing a c.262G>C (p.Gly88Arg) missense mutation in exon 2 (Fig. 3 and Table 1).

\section{Family 8 H}

Two male siblings showed polyuria and polydipsia from the age of 17 months and 19 months, respectively. Their mother, their maternal uncle as well as two maternal cousins had CDI (Fig. 1). The water deprivation test and the dDAVP tests confirmed diagnosis of CDI. 
Table 1 Age of onset in index cases and family members with vasopressin-neurophysin II gene mutations $(n=22)$.

\begin{tabular}{|c|c|c|c|}
\hline Families & $\begin{array}{l}\text { Age of onset } \\
\text { (months) }\end{array}$ & Mutation/exon & Exon \\
\hline Family $1 \mathrm{~A}$ & & & Exon II \\
\hline Index case & 32 & c.164C>T - (p.Pro55Leu) & \\
\hline Father & nd & c.164C>T - (p.Pro55Leu) & \\
\hline Family 2 B & & & Exonll \\
\hline Index case & 30 & c.322G > T - (p.Glu108X) & \\
\hline Father & 72 & & \\
\hline Family 3 C & & & Exonll \\
\hline Index case & 16 & c.287 G>A - (p.Gly96Asp) & \\
\hline Index case & 12 & c.287 G>A - (p.Gly96Asp) & \\
\hline Mother & 24 & c.287 G>A - (p.Gly96Asp) & \\
\hline Grandmother & 360 & c.287 G>A - (p.Gly96Asp) & \\
\hline Family $4 \mathrm{D}$ & & & Exonll \\
\hline Index case & 33 & c.164C>T - (p.Pro55Leu) & \\
\hline Sister & 22 & & \\
\hline Family $5 \mathrm{E}$ & & & Exon 1 \\
\hline Index case & 24 & c.56C>T (p.Ala19Val) & \\
\hline Father & 18 & c.56C>T (p.Ala19Val) & \\
\hline Family $6 \mathrm{~F}$ & & & Exonll \\
\hline Index case & 36 & c.287G >T - (p.Gly96Val) & \\
\hline Brother & 36 & & \\
\hline Mother & 72 & & \\
\hline Family $7 \mathrm{G}$ & & & Exonll \\
\hline Index case & $N A^{*}$ & c.262G >C - (p.Gly88Arg) & \\
\hline Family $8 \mathrm{H}$ & & & Exonll \\
\hline Index case & 17 & c.160G>C - (p.Gly54Arg) & \\
\hline Index case & 19 & c.160G>C - (p.Gly54Arg) & \\
\hline Mother & $N A^{* *}$ & c.160G>C - (p.Gly54Arg) & \\
\hline Family 9 I & & & Exon I \\
\hline Index case & 120 & c.55G >A - (p.Ala19Thr) & \\
\hline Index case & 120 & & \\
\hline Family $10 \mathrm{~J}$ & & & Exon I \\
\hline Index case & 120 & c.55G >A - (p.Ala19Thr) & \\
\hline Family $11 \mathrm{~K}$ & & & Exon I \\
\hline Index case & 132 & c.55G >A - (p.Ala19Thr) & \\
\hline Family $12 \mathrm{~L}$ & & & Exonll \\
\hline Index case & 132 & c.173 G>C - (p.Cys58Ser) & \\
\hline Brother & 120 & c.173 G>C - (p.Cys58Ser) & \\
\hline Family $13 \mathrm{M}$ & & & Exon II \\
\hline Index case & 3 & c.215 C>A - (p. Ala72Glu) & \\
\hline Father & 6 & c.215 C>A - (p. Ala72Glu) & \\
\hline
\end{tabular}

Brain MRI showed in both patients a normal anterior pituitary with absent posterior pituitary hyperintensity. The c.160G>C (p.Gly54Arg) missense mutation was detected (Fig. 3 and Table 1).

\section{Family 9 I}

Two female twins had clinical signs suggestive of DI from the age of 10 years. Their father and paternal grandmother had the same condition (Fig. 1). Genetic analysis showed a c.55G $>$ A (p.Ala19Thr) mutation in exon1 (Fig. 3 and Table 1).

\section{Family $10 \mathrm{~J}$}

The index case is a 49-year-old woman with clinical signs of DI from the age of 10 years. Five family members (sister, mother, maternal grandfather, uncle and cousin) (Fig. 1) showed the same clinical signs. The patient enjoyed good health and had two unaffected children. She had also Hashimoto's thyroiditis and was treated with levothyroxine. Genetic analysis showed c.55G $>$ A (p.Ala19Thr) mutation (Fig. 3 and Table 1).

\section{Family $11 \mathrm{~K}$}

This girl was a second child, born after 39-week gestation via vaginal delivery, her birth weight $(3.300 \mathrm{~kg})$ and length $(49 \mathrm{~cm})$ were appropriate for gestational age. She showed polyuria and polydipsia from the age of 9 years. Her mother and maternal grandfather showed the same symptoms (Fig. 1) (age of onset was not available). Brain MRI was normal, although PP data are not available (Table 2). Genetic tests showed c.55G $>$ A (p.Ala19Thr) heterozygous mutation (Fig. 3 and Table 1).

\section{Family $12 \mathrm{~L}$}

The index case is a girl with history of polyuria and polydipsia from the age of 11 years. Clinical evaluation at the age of 11 years showed a weight of $45.2 \mathrm{~kg}\left(25^{\circ}-50^{\circ}\right.$ centile), height $144.1 \mathrm{~cm}\left(3^{\circ}-25^{\circ}\right.$ centile $)$ with a normal growth velocity. Diagnosis of CDI was performed at the age of 12 years. Her brother had the same history with polyuria and polydipsia from the age of 10 years and diagnosis of CDI was performed at the age of 11 years. Clinical evaluation showed a normal height: $\mathrm{cm} 141.5$ $\left(25^{\circ}-50^{\circ}\right.$ centile) and weight: $\mathrm{kg} 36.9\left(50^{\circ}-75^{\circ}\right.$ centile) . Genetic tests revealed a new c.173G $>C$ (p.Cys58Ser) missense mutation in exon 2 (Fig. 3 and Table 1). The family tree is shown in Fig. 1.

\section{Family $13 \mathrm{M}$}

This boy was a second child, born at term; his birth weight $(4 \mathrm{~kg})$ and length $(52 \mathrm{~cm})$ were appropriate for gestational age. He showed polyuria and polydipsia from the first months of life. Diagnosis of CDI was performed at the age of 9 years. Brain MRI showed an undetectable PP signal. His father had the same history with polyuria 
Table 2 MRI findings in patients with vasopressin-neurophysin II gene mutations.

\begin{tabular}{l}
\hline Families/Members \\
\hline $1 \mathrm{~A}$ \\
Index case III1 \\
$2 \mathrm{~B}$ \\
Index case II1 \\
$3 \mathrm{C}$ \\
Index case IV1 \\
Mother-III2 \\
$4 \mathrm{D}$ \\
Index case III3 \\
Sister III4 \\
$5 \mathrm{E}$ \\
Index case IV1 \\
Index case MRI follow-up \\
$6 \mathrm{~F}$ \\
Index case IV2 \\
Brother IV1 \\
Mother III2 \\
$7 \mathrm{G}$ \\
Index case III1 \\
$8 \mathrm{H}$ \\
Index case II1 \\
$11 \mathrm{~K}$ \\
Index case III2 \\
$12 \mathrm{~L}$ \\
Index case III2 \\
$13 \mathrm{M}$ \\
Index case III2 \\
\hline
\end{tabular}

\begin{tabular}{l} 
Anterior pituitary \\
\hline Normal \\
Normal \\
Hypoplasia \\
Normal \\
Normal \\
Hypoplasia \\
Hypoplasia \\
Normal \\
Normal \\
Empty sella \\
Normal \\
Normal \\
Normal \\
Normal
\end{tabular}

\begin{tabular}{ll}
\hline Pituitary stalk & Posterior pituitary signal \\
\cline { 1 - 1 } Normal & Undetectable \\
Normal & Undetectable \\
Normal & Undetectable \\
Normal & Undetectable \\
Normal & Normal \\
Normal & Hypointense \\
Normal & Normal \\
Normal & Undetectable \\
Normal & Hypointense \\
Normal & Undetectable \\
Normal & Hypointense \\
Normal & Hypointense \\
Normal & Undetectable \\
Normal & Not available \\
Normal & Hypointense \\
Normal & Undetectable \\
\hline
\end{tabular}

and polydipsia from the age of 6 months. Diagnosis was performed at the age of 30 years. Genetic tests revealed a new c. 215C >A (p.Ala72Glu) missense mutation in exon 2 (Fig. 3 and Table 1). The family tree is shown in Fig. 1.

\section{MRI results}

Brain MRI was performed in 15 patients and the results are shown in Table 2. MRI results were not available for kindreds 9 and 10. The anterior pituitary was normal in 12 subjects, hypoplastic anterior pituitary/empty sella was found in 3; the pituitary stalk was normal in all patients and none displayed midline/central nervous system malformations. The PPI was undetectable in eight subjects, hypointense in four and normal in two. Follow-up MRI performed in one case showed a disappearance of the PP signal after 6 years. Anterior pituitary function was normal at the time of the first evaluation and during the follow-up in all patients. A diagnostic flow chart for genetic CDI is represented in Fig. 4.

\section{Discussion}

The present study defines clinical and molecular characteristics of 22 affected patients with familial central
DI from 13 different Italian families. Eight of the identified mutations were known to be associated with adNDI of the AVP-NPII gene and have previously been reported by others $(8,9,10,11,12,13,14,15,16,17,18,19,20,21$, $22,23,24,25,26,27,28,29,30,31,34,35,36,37,38,39$ ), while two novel mutations are here described for the first time. Genetic analyses revealed that all affected members were heterozygous for the mutations as expected from autosomal dominant mode of inheritance.

According to the literature, most of our affected patients carried a missense mutation, 8 of 10 involving the NPII which is an intracellular binding protein for AVP confirming that most mutations occur in gene regions encoding the NPII moiety (10). Since the first report of an AVP gene mutation causing adNDI (34), over 70 mutations have been listed in the Human Gene Mutation Database, most of them single base missense/nonsense substitutions, several small deletions $(22,35,36)$ or indels (22) and one splice-site mutation (26). The mutations are predicted to interfere with protein folding of the pre-prohormone, for example, by impaired binding of AVP to NPII (26), replacing $(22,29,37)$ or introducing $(21,22,38)$ cysteine residues or introducing premature stop codons $(22,25,39)$.

In our cohort, families 1 and 4 showed c.164C>T (p.Pro55leu) mutation that might alter the proper folding 
of the pro-hormone (34), while c.322G $>\mathrm{T}$ mutation detected in family 2 should produce an AVP mutant with a different C-terminus (starting at codon 108) and/or a truncated protein (p.Glu108X) (35). Families 3, 6 and 7 showed c.287G $>$ A, c. $287 \mathrm{G}>\mathrm{T}$ and c. $262 \mathrm{G}>\mathrm{C}$ mutations, which seem to cause a severe impairment of the AVP prohormone processing and secretion likely due to trapping in the $\mathrm{ER}(22,36)$, and c.56C $>\mathrm{T}$ (p.Ala19Val) mutation identified in family 5 causes possible abnormal prehormone processing (22). Family 8 showed the c.160G $>C$ (p.Gly54Arg) missense mutation, acting as the one described in family 2 (37). These two mutations alter the correct folding of the protein. The AVP mutants complex with the wild-type proteins to form heterodimers which are retained in endoplasmatic reticulum of secreting neurons. The mutant WT heterodimers lead to cytotoxic effects with gradual and progressive loss of viable neurosecretory neurons $(35,37)$. c.55G $>$ A (p.Ala19Thr) had been detected in families 9,10 and 11 (38). This latter mutation involves a residue of the signal peptide and could produce an abnormally processed precursor that gradually destroys vasopressinergic neurons (38).

Two novel mutations in Exon 2 of the AVP-NPII gene were found in families 12 and 13 , one being a single heterozygous missense mutation with a change G-to-C transversion at nucleotide position 173; as a consequence of this mutation, at position 58, cysteine is replaced by serine. The other mutation determines a change from C-to-A transversion at nucleotide position 215; due to the latter, at position 72 of the protein, alanine is predicted to be replaced by glutamic acid. These two novel mutations were not observed in the alleles of the unaffected members of the analyzed kindred and in 200 healthy controls. The late onset of the disease in family 12 may be explained by the fact that this new mutation causes a switch among neutral amino acids, which potentially does not severely affect the biochemical features of the mature protein. The hypothesized mechanisms underlying the phenotype of the two novel mutations could be explained by one of those extensively investigated in the cell lines of patients with adNDI $(8,16,17,33)$. Mutant AVP precursors reportedly accumulate and aggregate in the ER, which leads to defective intracellular trafficking of wild-type AVP protein and a decrease in cell viability. Furthermore, autophagy has been suggested to have a bifunctional role in cell survival and death in a transfected cell lineexpressing mutant NPII $(40,41)$, and recently, Hagiwara et al. demonstrated that although autophagy should primarily be a protective mechanism, continuous autophagy leads to gradual loss of organelles including ER,

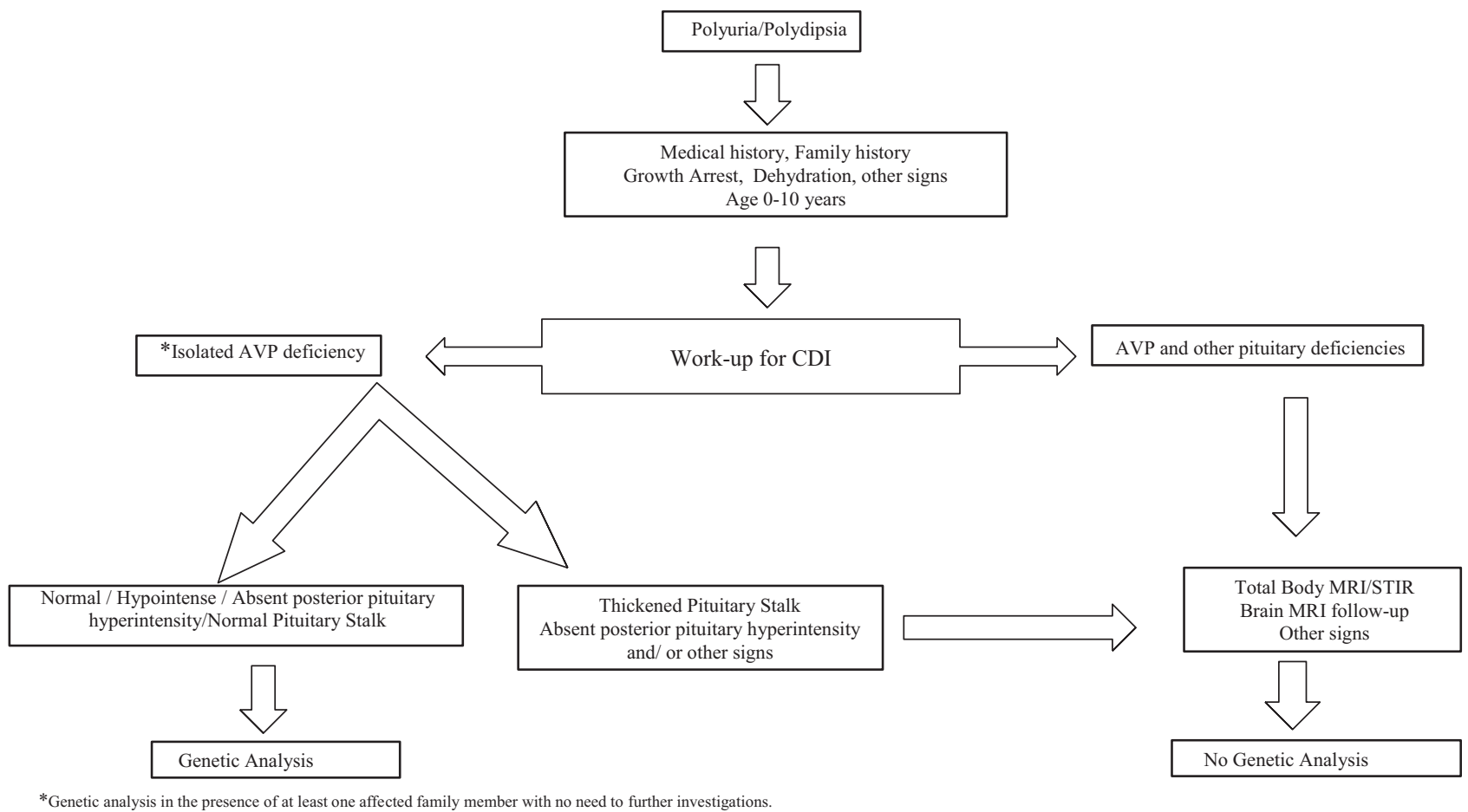

Figure 4

Diagnostic flow chart of familial central diabetes insipidus. 
resulting in autophagy-associated cell death of AVP neurons in mice with familial NDI mice (33).

In autosomal dominant CDI, clinical disease onset can be expressed during the neonatal period $(8,10)$, but typically polyuria and polydipsia in adNDI occur during the first months to years of life and progress as AVP deficiency becomes increasingly severe (8). In addition, the onset of disease and the severity of polyuria may vary considerably between different families and even among siblings who carry the same mutation (31). In our study, subjects carrying c.55G $>$ A (p.Ala19Thr) or c.173 G>C (p.Cys58Ser) mutations have a later onset of disease with the c.55G $>$ A (p.Ala19Thr) encoding for a mutation of the signal peptide, while the c.173 G>C (p.Cys58Ser) affecting NPII; both changes are among neutral amino acids, and they potentially will only have a mild effect on the biochemical features of the mature proteins, thus inducing a late onset of the inherited condition; c.55G $>$ A (p.Ala19Thr) mutation causing impaired signal cleavage has been associated with later onset of clinical signs (30, 39). The median age of disease onset in our patients was found to be slightly higher than the average age reported in the literature (24 months) for several reasons, above all because of the inaccurate time of diagnosis, since the first symptoms of polyuria and polydipsia may lead to disease underestimation, especially in families with many affected members where such symptoms can be considered 'physiological'. We believe that the rarity and heterogeneity of the mutations published so far produces a variety of clinical features that would require a systematic analysis of the genotype-phenotype correlation in larger cohorts.

In the present study, the PPI was undetectable in eight subjects, hypointense in four and normal in two in agreement with our previous findings in small cohorts and with the literature $(1,3,5,7)$. Although $10 \%$ of normal individuals do not display PPI (40), its absence in patients with CDI is always associated with hypothalamicneurohypophyseal axis lesion and correlates closely with undetectable plasma AVP (41). This suggests that evidence of PPI does not rule out diagnosis of CDI, as release of stored AVP may be impaired in some cases of autosomal dominant DI. Thus, the identification of PP signal does not necessarily indicate that the functional integrity of the hypothalamic-neurohypophyseal axis is preserved and - when initially present - the signal may disappear at follow-up. Similar findings were also reported by our group in patients with de novo mutations of AVP gene who were classified as affected by 'idiopathic' CDI (7).

In conclusion, we describe the clinical, molecular and imaging characteristics of 22 members of 13 Italian families with adNDI, with 8 previously reported mutations and two novel mutations in two different families. aFNDI is a progressive disease with a variable age of onset and severity. Posterior pituitary hyperintensity may be present or hypointense, with a loss of the MRI signal over time suggesting that persistence of the hyperintensity in isolated and early-onset CDI should favor the diagnosis of adNDI. Molecular analysis of AVP-NPII gene and counseling should be provided in selected cases to avoid unnecessary investigations and to ensure an early and adequate treatment.

\section{Supplementary data}

This is linked to the online version of the paper at https://doi.org/10.1530/ EJE-19-0299.

\section{Declaration of interest}

The authors declare that there is no conflict of interest that could be perceived as prejudicing the impartiality of this study.

\section{Funding}

This research did not receive any specific grant from any funding agency in the public, commercial or not-for-profit sector.

\section{Acknowledgement}

All authors approved the final manuscript as submitted and agree to be accountable for all aspects of the work.

\section{References}

1 Maghnie M, Cosi G, Genovese E, Manca-Bitti ML, Cohen A, Zecca S, Tinelli C, Gallucci M, Bernasconi S, Boscherini B et al. Central diabetes insipidus in children and young adults. New England Journal of Medicine 2000343 998-1007. (https://doi.org/10.1056/ NEJM200010053431403)

2 Di Iorgi N, Morana G, Napoli F, Allegri AE, Rossi A \& Maghnie M. Management of diabetes insipidus and adipsia in the child. Best Practice and Research: Clinical Endocrinology and Metabolism 201529 415-436. (https://doi.org/10.1016/j.beem.2015.04.013)

3 Di Iorgi N, Allegri AE, Napoli F, Calcagno A, Calandra E, Fratangeli N, Vannati M, Rossi A, Bagnasco F, Haupt R et al. Central diabetes insipidus in children and young adults: etiological diagnosis and long-term outcome of idiopathic cases. Journal of Clinical Endocrinology and Metabolism 201499 1264-1272. (https://doi. org/10.1210/jc.2013-3724)

4 Di Iorgi N, Napoli F, Allegri AE, Olivieri I, Bertelli E, Gallizia A Rossi A \& Maghnie M. Diabetes insipidus-diagnosis and management. Hormone Research in Paediatrics 201277 69-84. (https://doi.org/10.1159/000336333)

5 Maghnie M, Ghirardello S, De Bellis A, di Iorgi N, Ambrosini L, Secco A, De Amici M, Tinelli C, Bellastella A \& Lorini R. Idiopathic central diabetes insipidus in children and young adults is commonly associated with vasopressin-cell antibodies and markers of autoimmunity. Clinical Endocrinology 200665 470-478. (https://doi. org/10.1111/j.1365-2265.2006.02616.x)

6 Maghnie M, Altobelli M, Di Iorgi N, Genovese E, Meloni G, MancaBitti ML, Cohen A \& Bernasconi S. Idiopathic central diabetes 
insipidus is associated with abnormal blood supply to the posterior pituitary gland caused by vascular impairment of the inferior hypophyseal artery system. Journal of Clinical Endocrinology and Metabolism 200489 1891-1896. (https://doi.org/10.1210/jc.2003031608)

7 Werny D, Elfers C, Perez FA, Pihoker C \& Roth CL. Pediatric central diabetes insipidus: brain malformations are common and few patients have idiopathic disease. Journal of Clinical Endocrinology and Metabolism 2015100 3074-3080. (https://doi.org/10.1210/jc.2015-1287)

8 Perrotta S, Di Iorgi N, Ragione FD, Scianguetta S, Borriello A, Allegri AE, Ferraro M, Santoro C, Napoli F, Calcagno A et al. Earlyonset central diabetes insipidus is associated with de novo arginine vasopressin-neurophysin II or Wolfram syndrome 1 gene mutations. European Journal of Endocrinology 2015172 461-472. (https://doi. org/10.1530/EJE-14-0942)

9 Babey M, Kopp P \& Robertson GL. Familial forms of diabetes insipidus: clinical and molecular characteristics. Nature Reviews: Endocrinology 20117 701-714. (https://doi.org/10.1038/ nrendo.2011.100)

10 Rutishauser J, Spiess M \& Kopp P. Genetic forms of neurohypophyseal diabetes insipidus. Best Practice and Research: Clinical Endocrinology and Metabolism 201630 249-262. (https://doi. org/10.1016/j.beem.2016.02.008)

11 Schernthaner-Reiter MH, Stratakis CA \& Luger A. Genetics of diabetes insipidus. Endocrinology and Metabolism Clinics of North America 2017 46 305-334. (https://doi.org/10.1016/j.ecl.2017.01.002)

12 Christensen JH \& Rittig S. Familial neurohypophyseal diabetes insipidus - an update. Seminars in Nephrology 200626 209-223. (https://doi.org/10.1016/j.semnephrol.2006.03.003)

13 Willcutts MD, Felner E \& White PC. Autosomal recessive familial neurohypophyseal diabetes insipidus with continued secretion of mutant weakly active vasopressin. Human Molecular Genetics 19998 1303-1307. (https://doi.org/10.1093/hmg/8.7.1303)

14 Abu Libdeh A, Levy-Khademi F, Abdulhadi Atwan M, Bosin E, Korner M, White PC \& Zangen DH. Autosomal recessive familial neurohypophyseal diabetes insipidus: onset in early infancy. European Journal of Endocrinology 2010162 221-226. (https://doi. org/10.1530/EJE-09-0772)

15 Bourdet K, Vallette S, Deladoëy J \& Van Vliet G. Early-onset central diabetes insipidus due to compound heterozygosity for AVP mutations. Hormone Research in Paediatrics 201685 283-287. (https:// doi.org/10.1159/000441844)

16 Bichet DG. Genetics and diagnosis of central diabetes insipidus. Annales d'Endocrinologie 201273 117-127. (https://doi.org/10.1016/j. ando.2012.03.030)

17 Birkegaard C, Christensen JH, Falorni A, Marzotti S, Minarelli V, Gregersen N \& Rittig S. A novel variation in the AVP gene resulting in familial neurohypophyseal diabetes insipidus in a large Italian kindred. Pituitary 201316 152-157. (https://doi.org/10.1007/s11102012-0392-x)

18 Koufaris C, Alexandrou A, Sismani C \& Skordis N. Identification of an AVP-NPII mutation within the AVP moiety in a family with neurohypophyseal diabetes insipidus: review of the literature. Hormones 201514 442-446. (https://doi.org/10.14310/ horm.2002.1604)

19 Ilhan M, Tiryakioglu NO, Karaman O, Coskunpinar E, Yildiz RS, Turgut S, Tiryakioglu D, Toprak H \& Tasan E. A novel AVP gene mutation in a Turkish family with neurohypophyseal diabetes insipidus. Journal of Endocrinological Investigation 201639 285-290. (https://doi.org/10.1007/s40618-015-0357-9)

20 McLeod JF, Kovacs L, Gaskill MB, Rittig S, Bradley GS \& Robertson GL. Familial neurohypophyseal diabetes insipidus associated with a signal peptide mutation. Journal of Clinical Endocrinology and Metabolism 199377 599A-599G. (https://doi. org/10.1210/jcem.77.3.8370682)
21 Christensen JH, Siggaard C, Corydon TJ, deSanctis L, Kovacs L, Robertson GL, Gregersen N \& Rittig S. Six novel mutations in the arginine vasopressin gene in 15 kindreds with autosomal dominant familial neurohypophyseal diabetes insipidus give further insight into the pathogenesis. European Journal of Human Genetics 200412 44-51. (https://doi.org/10.1038/sj.ejhg.5201086)

22 Rittig S, Robertson GL, Siggaard C, Kovács L, Gregersen N, Nyborg J \& Pedersen EB. Identification of 13 new mutations in the vasopressin-neurophysin II gene in 17 kindreds with familial autosomal dominant neurohypophyseal diabetes insipidus. American Journal of Human Genetics 199658 107-117.

23 Rittig S, Siggaard C, Ozata M, Yetkin I, Gregersen N, Pedersen EB \& Robertson GL. Autosomal dominant neurohypophyseal diabetes insipidus due to substitution of histidine for tyrosine (2) in the vasopressin moiety of the hormone precursor. Journal of Clinical Endocrinology and Metabolism 200287 3351-3355. (https://doi. org/10.1210/jcem.87.7.8677)

24 Kobayashi H, Fujisawa I, Ikeda K, Son C, Iwakura T, Yoshimoto A, Kasahara M, Ishihara T \& Ogawa Y. A novel heterozygous missense mutation in the vasopressin moiety is identified in a Japanese person with neurohypophyseal diabetes insipidus. Journal of Endocrinological Investigation 200629 252-256. (https://doi.org/10.1007/BF03345549)

25 de Fost M, van Trotsenburg AS, van Santen HM, Endert E, van den Elzen C, Kamsteeg EJ, Swaab DF \& Fliers E. Familial neurohypophyseal diabetes insipidus due to a novel mutation in the arginine vasopressin-neurophysin II gene. European Journal of Endocrinology 2011165 161-165. (https://doi.org/10.1530/EJE-110048)

26 Tae HJ, Baek KH, Shim SM, Yoo SJ, Kang MI, Cha BY, Lee KW, Son HY $\&$ Kang SK. A novel splice site mutation of the arginine vasopressinneurophysin II gene identified in a kindred with autosomal dominant familial neurohypophyseal diabetes insipidus. Molecular Genetics and Metabolism 200586 307-313. (https://doi.org/10.1016/j. ymgme.2005.05.009)

27 Calvo B, Bilbao JR, Urrutia I, Eizaguirre J, Gaztambide S \& Castaño L. Identification of a novel nonsense mutation and a missense substitution in the vasopressin-neurophysin II gene in two Spanish kindreds with familial neurohypophyseal diabetes insipidus. Journal of Clinical Endocrinology and Metabolism 199883 995-997. (https:// doi.org/10.1210/jcem.83.3.4658)

28 Bullmann C, Kotzka J, Grimm T, Heppner C, Jockenhövel F, Krone W $\&$ Müller-Wieland D. Identification of a novel mutation in the arginine vasopressin-neurophysin II gene in familial central diabetes insipidus. Experimental and Clinical Endocrinology and Diabetes 2002 110 134-137. (https://doi.org/10.1055/s-2002-29091)

29 Rutishauser J, Kopp P, Gaskill MB, Kotlar TJ \& Robertson GL. Clinical and molecular analysis of three families with autosomal dominant neurohypophyseal diabetes insipidus associated with a novel and recurrent mutations in the vasopressin-neurophysin II gene. European Journal of Endocrinology 2002146 649-656. (https://doi.org/10.1530/ eje.0.1460649)

30 Cizmarova M, Nagyova G, Janko V, Pribilincova Z, Virgova D, Ilencikova D \& Kovacs L. Late onset of familial neurogenic diabetes insipidus in monozygotic twins. Endocrine Regulations 201347 211-216. (https://doi.org/10.4149/endo_2013_04_211)

31 Repaske DR, Medlej R, Gultekin EK, Krishnamani MR, Halaby G, Findling JW \& Phillips JA. Heterogeneity in clinical manifestation of autosomal dominant neurohypophyseal diabetes insipidus caused by a mutation encoding Ala-1->Val in the signal peptide of the arginine vasopressin/neurophysin II/copeptin precursor. Journal of Clinical Endocrinology and Metabolism 199782 51-56. (https://doi. org $/ 10.1210 /$ jcem.82.1.3660)

32 Djermane A, Elmaleh M, Simon D, Poidvin A, Carel JC \& Léger J. Central diabetes insipidus in infancy with or without hypothalamic adipsic hypernatremia syndrome: early identification and outcome. 
Journal of Clinical Endocrinology and Metabolism 2016101 635-643. (https://doi.org/10.1210/jc.2015-3108)

33 Hagiwara D, Grinevich V \& Arima H. A novel mechanism of autophagy-associated cell death of vasopressin neurons in familial neurohypophysial diabetes insipidus. Cell and Tissue Research 2019 375 259-266. (https://doi.org/10.1007/s00441-018-2872-4)

34 Repaske DR \& Browning JE. A de novo mutation in the coding sequence for neurophysin-II (Pro24-->Leu) is associated with onset and transmission of autosomal dominant neurohypophyseal diabetes insipidus. Journal of Clinical Endocrinology and Metabolism 199479 421-427. (https://doi.org/10.1210/jcem.79.2.8045958)

35 de Fost M, van Trotsenburg AS, van Santen HM, Endert E, van den Elzen C, Kamsteeg EJ, Swaab DF \& Fliers E. Familial neurohypophyseal diabetes insipidus due to a novel mutation in the arginine vasopressin-neurophysin II gene. European Journal of Endocrinology 2011165 161-165. (https://doi.org/10.1530/EJE-110048)

36 Christensen JH, Siggaard C, Corydon TJ, deSanctis L, Kovacs L, Robertson GL, Gregersen N \& Rittig S. Six novel mutations in the arginine vasopressin genein 15 kindreds with autosomal dominant familial neurohypophyseal diabetes insipidus give further. Insights into the pathogenesis. European Journal of Human Genetics 200412 44-51. (https://doi.org/10.1038/sj.ejhg.5201086)
37 Heppner C, Kotzka J, Bullmann C, Krone W \& Müller-Wieland D. Identification of mutations of the arginine vasopressin-neurophysin II gene in two kindreds with familial central diabetes insipidus. Journal of Clinical Endocrinology and Metabolism 199883 693-696. (https://doi.org/10.1210/jcem.83.2.4571)

38 McLeod JF, Kovács L, Gaskill MB, Rittig S, Bradley GS \& Robertson GL. Familial neurohypophyseal diabetes insipidus associated with a signal peptide mutation. Journal of Clinical Endocrinology and Metabolism 199377 599A-599G. (https://doi. org/10.1210/jcem.77.3.8370682)

39 Jendle J, Christensen JH, Kvistgaard H, Gregersen N \& Rittig S. Lateonset familial neurohypophyseal diabetes insipidus due to a novel mutation in the AVP gene. Clinical Endocrinology 201277 586-592. (https://doi.org/10.1111/j.1365-2265.2012.04417.x)

40 Di Iorgi N, Allegri AE, Napoli F, Bertelli E, Olivieri I, Rossi A \& Maghnie M. The use of neuroimaging for assessing disorders of pituitary development. Clinical Endocrinology 201276 161-176. (https://doi.org/10.1111/j.1365-2265.2011.04238.x)

41 Maghnie M, Villa A, Arico' M, Larizza D, Pezzotta S, Beluffi G, Genovese E \& Severi F. Correlation between magnetic resonance imaging of posterior pituitary and neurohypophyseal function in children with diabetes insipidus. Journal of Clinical Endocrinology and Metabolism 199274 795-800.

Received 19 April 2019

Revised version received 11 June 2019

Accepted 24 June 2019 